\title{
DIFLUOROMETHYL 1,1,2-TRIFLUORO-2-CHLOROETHYL ETHER AS AN ANAESTHETIC AGENT: RESULTS WITH DOGS, AND A PRELIMINARY NOTE ON OBSERVATIONS WITH MAN ${ }^{*}$
}

\author{
ROBert W. ViRTUE, M.D., PH.D., LAWRENCE O. LUND, M.D., \\ McKinley Pheips, JR., M.D., John H. K. Vogel, M.D., \\ HeNRY BeCKWITT, M.D., AND MICHaEd Heron $\nmid$
}

DuRING THE continuIng SEARCH for better anaesthetic agents, a new compound, difluoromethyl 1,1,2-trifluoro-2-chloroethyl ether $\left(\mathrm{CF}_{2} \mathrm{H}-\mathrm{O}-\mathrm{CF}_{2} \mathrm{CFClH}\right)$, hereinafter DFMTFCE, which had appeared to be valuable in preliminary testing, was offered to us for further study. The substance is a non-explosive colourless liquid with a pleasing aromatic odor. Its molecular weight is 184.5 and its boiling point is $56.5^{\circ} \mathrm{C}$. The vapour pressure at $25^{\circ}$ is $250 \mathrm{~mm} . \mathrm{Hg}$, and the specific gravity is $1.51 \mathrm{n}_{\mathrm{D}}{ }^{20}=1.3026$ to 1.3030 . The compound is stable on storage, needing no dark bottles or stabilizers. Our early experiments with dogs showed that smooth and rapid anaesthesia could be obtained. Cardiovascular and respiratory studies were then carried out on non-operated volunteers, and when these appeared to show satisfactory values, DFMTFCE was administered to a few patients undergoing surgical procedures.

\section{Materuals and Methods}

Six unpremedicated fasting dogs were anaesthetized with open-drop technique using DFMTFCE of 99.95 per cent purity. Induction was smooth, rapid, and not accompanied by noticeable salivation. During sleep, respiration was regular and adequate. Subsequently, two dogs were anaesthetized with DFMTFCE on alternate days for an hour each time until each had been anaesthetized seven times. The trachea of each dog was intubated, and anaesthesia was maintained with DFMTFCE and oxygen with spontaneous respiration. Each animal was given epinephrine according to the technique of Meek, Hathaway, and Orth ${ }^{1}$ before administration of the agent was stopped. At the termination of the seventh anesthetic period biopsy specimens of lung, heart, kidney, and liver were removed.

In 16 dogs, glucose, ${ }^{2}$ urea nitrogen, ${ }^{3}$ aldolase, ${ }^{4}$ isocitric dehydrogenase, ${ }^{5}$ serum glutamic oxalic transaminase, ${ }^{6}$ serum glutamic pyruvic transaminase, ${ }^{6,7}$ lactic acid dehydrogenase ${ }^{8}$ and leucine amino peptidase ${ }^{0}$ were determined. After one hour of DFMTFCE, epinephrine was injected as above and the same studies were repeated. The enzyme determinations were repeated two days later.

"Supported by a grant from the Air Reduction Company.

†Division of Anesthesiology and the Cardiovascular Laboratory, University of Colorado Medical Center, Denver, Colorado. Drs. Virtue, Lund, and Phelps are respectively Professor, Instructor, and Resident in Anesthesiology. Drs. Vogel and Beckwitt are respectively Advanced Research Fellow, American Heart Association, and Instructor in Medicine, supported by the Idaho Heart Association. Mr. Heron is a Research Associate. 
Latin Square

Four additional dogs were used to compare the effects of halothane, methoxyflurane, fluroxene, and DFMTFCE in a latin square project. Control BSP retention measurements were made, and blood was taken for the same enzyme studies mentioned previously. The order of administration of the drugs was as follows:

$\begin{array}{lllll}\text { Dog 1 } & \text { Halothane } & \text { Fluroxene } & \text { Methoxyflurane } & \text { DFMTFCE } \\ \text { Dog 2 } & \text { Fluroxene } & \text { Methoxyflurane } & \text { DFMTFCE } & \text { Halothane } \\ \text { Dog 3 } & \text { Methoxyflurane } & \text { DFMTFCE } & \text { Halothane } & \text { Fluroxene } \\ \text { Dog 4 } & \text { DFMTFCE } & \text { Halothane } & \text { Fluroxene } & \text { Methoxyflurane }\end{array}$

Each animal was anaesthetized by the open-drop method and the trachea was intubated. No premedication was used. Anaesthesia in each animal was maintained with a surgical concentration of the respective agent for two hours using a circle absorption system with intermittent positive pressure ventilation so that each animal had a tidal volume of $30 \mathrm{cc} . / \mathrm{kg}$. 20 times per minute. Blood samples were taken for enzyme analysis at the end of each two-hour period, and a BSP retention test was done. BSP and enzyme tests were done again two days later. At least seven days elapsed between anaesthetics given to each dog. End tidal gas was analysed chromatographically for concentration of each agent.

\section{Volunteers}

Each of eight healthy volunteer subjects between 22 and 29 years of age was given atropine sulfate $0.4 \mathrm{mg} . / 70 \mathrm{~kg}$. intravenously. A short length of polyethylene 160 tubing was introduced into the brachial artery by the Seldinger ${ }^{10}$ technique. A polyethylene 60 tube was introduced into the antecubital vein either percutaneously or via a 16-gauge thin-walled needle. Blood pressures were recorded via a $\mathbf{P}_{\mathbf{2 3 d b}}$ transducer and recorded with a photographic oscillograph. * Arterial blood samples were withdrawn for determination of $\mathrm{pH}$, glucose, urea nitrogen, aldolase, isocitric dehydrogenase, serum glutamic oxaloacetic transaminase, glutamic pyruvic transaminase, leucine aminopeptidase, and lactic acid dehydrogenase. $^{2-9}$ Several measurements were made of total volume and respiratory rate until a minimum steady state had been reached. Control tidal volume, respiratory rate, and exhaled air samples were then taken. Cardiac output was measured, the cardiogreen dye being injected simultaneously with taking the air samples. The subjects were then anaesthetized with DFMTFCE and oxygen using a closed circle absorption system. After moderately deep surgical anaesthesia had been attained, the trachea was intubated and a non-rebreathing system was used, maintaining the same tidal volume and minute volume that had been measured with spontaneous respiration. After 15 minutes of a steady state which was coincident with initial burst suppression by electroencephalogram (E.E.G.), cardiac output, pressures, and respiratory measurements were again determined. Blood samples were taken for the same studies as before. The subject was then ventilated with room air and the agent continued at a stable E.E.G. level for another 15 minutes. Circulatory and respiratory data were again obtained, and blood samples were again withdrawn. The DFMTFCE was discontinued, the subjects were ventilated with oxygen and permitted to awaken.

-Electronics for Medicine, White Plains, New York. 


\section{Surgical Patients}

Eleven patients having surgical procedures were given DFMTFCE as their anaesthetic agent. Each patient had received meperidine $100 \mathrm{mg} . / 70 \mathrm{~kg}$. and scopolamine $0.4 \mathrm{mg} . / 70 \mathrm{~kg}$. intramuscularly an hour prior to induction. Four were induced with thiopental, and seven were induced by mask using only oxygen and DFMTFCE. All were maintained in surgical anaesthesia using a semi-closed system with 500 c.c. each of nitrous oxide and oxygen, plus sufficient DFMTFCE as necessary for analgesia.

Surgical procedures were: debridement of humerus (1), conization of uterus (4), dilatation and curettage (1), vaginal hysterectomy (3), abdominal tubal ligation (2).

\section{ResUlts}

\section{Preliminary Experiences with Dogs}

Induction with DFMTFCE by the open-drop method was smooth and rapid, requiring about two minutes. Subsequent anaesthetizations required about the same period of time. The drug did not appear to be irritating, and its use was accompanied by very little salivation both during and after induction. Respiration following induction was smooth and regular. With deeper anaesthesia respiration was depressed in both volume and rate. Emergence was rapid, and righting reflexes were regained without vomiting. Ataxia was brief. During anaesthesia the animals were quiet and well relaxed. Recovery appeared to be complete within a few minutes.

\section{Repeated Administrations to Dogs}

Each of the two dogs that were anaesthetized seven times with DFMTFCE gained weight during the two-week period. No nausea was evident following anaesthesia. Each animal regained its righting reflex within a few minutes after administration of the agent was stopped, and after an hour of anaesthesia: dog 1, $4 \pm 0.76 \mathrm{~min}$.; $\operatorname{dog} 2,3.3 \pm 0.30 \mathrm{~min}$. Both drank almost immediately on return to their runs. The report of the pathologist at the State Veterinary School was "normal canine tissue" on each specimen.

\section{Chemistry and Enzyme Studies in Dogs}

The enzyme studies before, at the end of, and two days following hour-long administration of DFMTFCE showed no significant changes (Table I). Nor was there any significant change in urea nitrogen data. Blood glucose was significantly elevated during the hour of anaesthesia, increasing from 88 to $101(p<0.01)$. Two days later the value was found to be $87 \mathrm{mg}$. per cent.

\section{EPINEPHRINE}

In three of 16 dogs that were anaesthetized with DFMTFCE, ventricular fibrillation occurred immediately after injection of epinephrine.

\section{Latin Square Experiments}

Determination of enzyme values during and after anaesthesia with animals that had each received DFMTFCE, halothane, fluroxene, and methoxyflurane 
TABLE I

Blood Glucose, BUN, and Enzyme Values after Administration of DFMTFCE TO 16 DOGS FOR ONE HOUR

\begin{tabular}{llcccc}
\hline \hline & & & & \multicolumn{2}{c}{$\begin{array}{c}\text { Normal } \\
\text { values in our } \\
\text { lab. }\end{array}$} \\
\hline 1 & Glucose & $88.1 \pm 3.3 \mathrm{mg} . \%$ & $101.2 \pm 3.2 \mathrm{mg} . \%^{*}$ & 87 & $75-130$ \\
2 & BUN & $17.2 \pm 1.3$ & $18.8 \pm 1.4$ & $\overline{2}$ & $10-22$ \\
3 & Aldolase & $2.1 \pm .28$ & $2.4 \pm .29$ & $2.2 \pm .27$ & $3-8$ \\
4 & ICD & $29 \pm 3.0$ & $28 \pm 2.8$ & $24 \pm 2.7$ & $50-275$ \\
5 & SGOT & $51 \pm 4.3$ & $64 \pm 8.2$ & $52 \pm 8.6$ & $0-25$ \\
6 & SGPT & $36 \pm 3.9$ & $1.41 \pm 3.4$ & $42 \pm 9.7$ & $0-35$ \\
7 & SGOT/SGPT & $1.60 \pm .16$ & $1.56 \pm .18$ & $1.40 \pm .16$ & $>1.0$ \\
8 & LDH & $116 \pm 8.0$ & $111 \pm 9.4$ & $125 \pm 7.8$ & $100-350$ \\
9 & LAP & $224 \pm 23$ & $323 \pm 75$ & $261 \pm 38$ & $70-230$ \\
\hline
\end{tabular}

showed no significant changes (Table II). Average end-tidal concentrations of the four agents during surgical anaesthesia in these non-premedicated dogs were: DFMTFCE 3.4 per cent, halothane 1.54 per cent, fluroxene 4.32 per cent, and methoxyflurane 0.16 per cent (Table III).

Urea nitrogen values were essentially the same before and after anaesthesia of two hours with each of the agents. Glucose rose moderately with each agent (N.S. for methoxyflurane, $p<0.01$ for the other three; see Table II). Two dogs had a measurable bromsulphathalein retention after fluroxene ( $6 \%$ each), one after methoxyflurane (7\%) and one after DFMTFCE (13\%), but all figures had returned below the minimal measurable value (2\%) within two days.

When the dogs were sufficiently deeply anaesthetized with DFMTFCE for the E.E.G. to demonstrate burst suppression, there frequently appeared spontaneous twitching motions. These could be elicited by striking the operating table or by making a sudden loud noise in the dog's ear. Twitching occurred only when the animals were in fairly deep anaesthesia and might be considered to be a warning that considerable depth had been reached. The motions could be stopped either by lowering the concentration of the agent or by administering thiopental intravenously.

\section{Volunteer Subjects}

Induction with DFMTFCE and oxygen was smooth and rapid. No salivation and very little muscular motion of extremities occurred in spite of the fact that two of the subjects weighed $100 \mathrm{~kg}$. each and no depressant medication had been given. The effects of the agent were similar to those seen with halothane. Blood pressure and cardiac output diminished on induction. Spontaneous respiration nearly ceased as anaesthesia became more profound. By pinching and using other stimuli short of incision it was possible to elicit responses similar to those expected with halothane, greater than those expected with nitrous oxide, and smaller than those expected with cyclopropane. Two subjects carried to "burst suppression" exhibited brief spontaneous twitches that disappeared quickly on removal of the agent.

Changes from oxygen to air were occasionally accompanied by mild hypoxaemia and an increase in cardiac output (Table IV). 


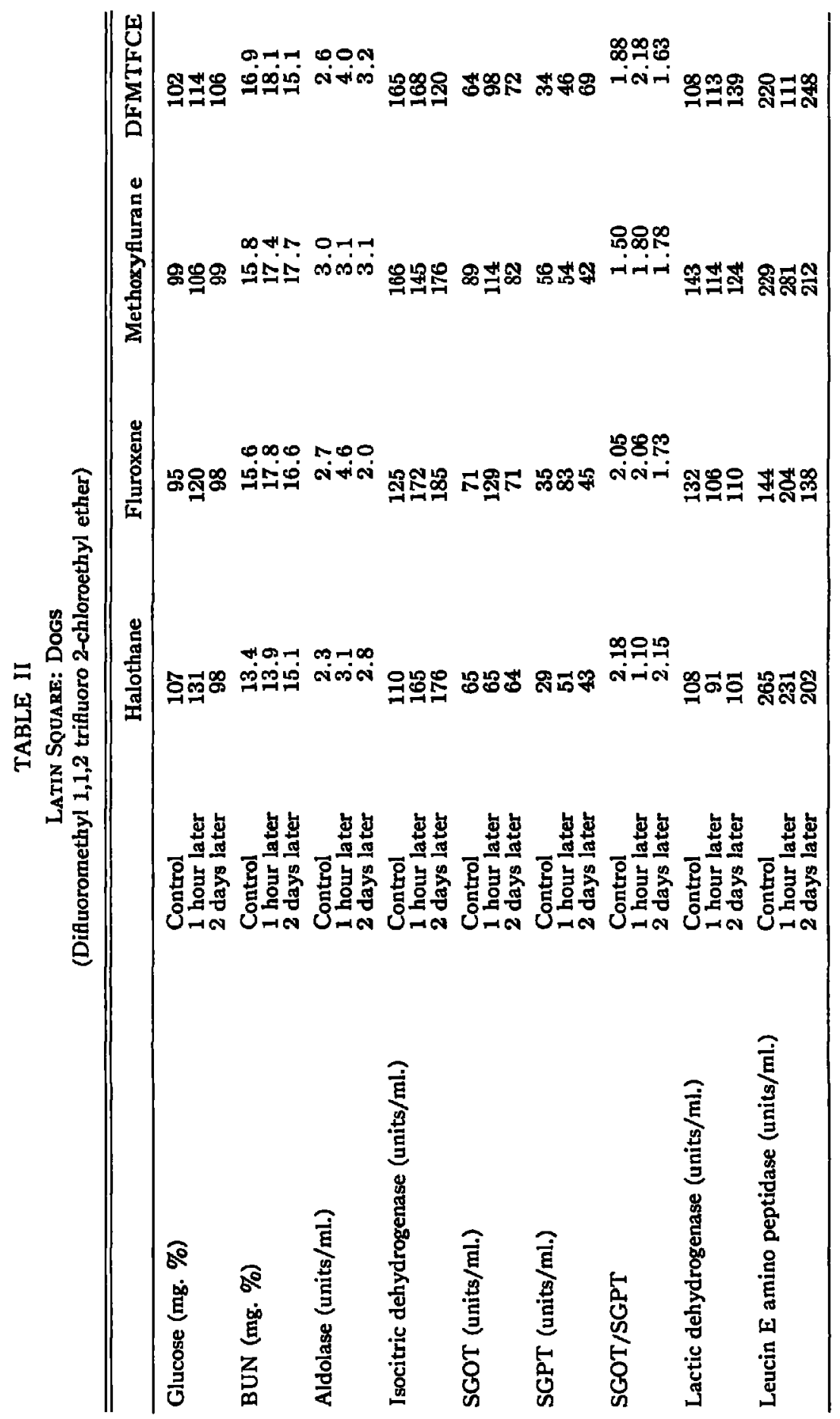


TABLE III

LaTiN SQUaRE: 4 Dogs

\begin{tabular}{lccr}
\hline \hline & \multicolumn{3}{c}{ Concentration of agents (\%) } \\
\cline { 2 - 4 } & 1 hour & 2 hours & Average \\
\hline Halothane & 1.68 & 1.39 & 4.54 \\
DFMTFCE & 3.46 & 3.33 & 3.40 \\
Fluroxene & 5.21 & 3.43 & 4.32 \\
Methoxyflurane & 0.21 & 0.15 & 0.18 \\
\hline
\end{tabular}

TABLE IV

Respiratory and Cardiovascular Measurements of 8 Volunteer Subjects WITH DFMTFCE

\begin{tabular}{lccc}
\hline \hline & Control & Asleep with oxygen & $\begin{array}{c}\text { Asleep with } \\
\text { compressed air }\end{array}$ \\
\hline Cardiac output (L./min.) & $6.60 \pm 0.92$ & $5.31 \pm 1.25$ & $6.22 \pm 2.25$ \\
Blood pressure (mg./Hg) & & & \\
$\quad$ systolic & $120 \pm 5.4$ & $80 \pm 4.7^{* * *}$ & $79 \pm 2.4^{* * *}$ \\
$\quad$ venous & $8 \pm 1.7$ & $8 \pm 1.7$ & $7 \pm 1.3$ \\
Pulse beats/min. & $72 \pm 2.4$ & $86 \pm 4.8^{* *}$ & $89 \pm 7.2^{*}$ \\
$\mathrm{Pog}_{\mathrm{g}} \mathrm{mm} . / \mathrm{Hg}$ & $76.6 \pm 2.5$ & $406 \pm 19.6^{* * *}$ & $65.7 \pm 6.9$ \\
$\mathrm{P}_{2} \mathrm{~mm} / \mathrm{Hg}$ & $35.9 \pm 1.3$ & $44.4 \pm 2.6$ & $47.0 \pm 3.0^{* *}$ \\
\hline
\end{tabular}

Statistical significance compared to control values:

${ }^{*} \mathrm{p}<0.05$.

$* \mathrm{p}<0.01$.

$* * *_{\mathrm{p}}<0.001$.

Recovery periods differed markedly among the eight subjects. One ate, drank, and went to work on his regular eight-hour shift 75 minutes after administration of DFMTFCE was discontinued. Another took his wife to dinner 90 minutes postanaesthetically. Three subjects were nauseated for an hour. One was delirious for an hour. All but two responded to commands within 10 minutes after administration was stopped. None remembered the induction as being unpleasant. Enzyme studies showed no abnormalities at the end of the procedure. All have been observed for at least six months since the measurements, and there have been no noticeable sequellae. Glucose rose in these subjects from an average 123 to $131 \mathrm{mg}$. per cent (N.S.). Urea nitrogen values were not significantly changed (Table V).

\section{Surgical Patients}

In seven of the eleven subjects anaesthesia was induced using only DFMTFCE and oxygen. None reported feeling that it was unpleasant. Blood pressure was generally diminished following induction, dropping an average of $25 \mathrm{~mm}$. $\mathrm{Hg}$ from the highest to the lowest systolic values. All pressures returned to control values when administration of the drug ceased. One patient who was carried to burst suppression (E.E.G.) demonstrated twitching in response to a loud noise. Relaxation was adequate for abdominal surgery. Ten of the eleven patients were awake by the time they had reached the recovery room. One vomited moderately. The patient who did not waken until after she had reached the recovery room 
TABLE V

Blood Analyses in Volunteer Subjects Receiving DFMTFCE as an ANAESTHETIC AGENT

\begin{tabular}{lccc}
\hline \hline & Awake & $\begin{array}{c}\text { DFMTFCE } \\
\text { with oxygen }\end{array}$ & $\begin{array}{c}\text { DFMTFCE } \\
\text { with air }\end{array}$ \\
\hline Glucose & $123.0 \pm 9$ & $131.0 \pm 8.4$ & $138.0 \pm 7$ \\
BUN & $20.5 \pm 1.8$ & $20.9 \pm 1.6$ & $20.3 \pm 109$ \\
Aldolase & 4 & 7 & 4 \\
ICD & 186 & 191 & 189 \\
SGOT & 9 & 8 & 8 \\
SGPT & 6 & 6 & 5 \\
SGOT/SGPT & 1.3 & 1.6 & 1.8 \\
LAD & 255 & 231 & 212 \\
LAP & 95 & 102 & 100 \\
\hline
\end{tabular}

No significant differences.

was 65 years of age and had probably been carried in deeper anaesthesia than was necessary for the surgical procedure. Beginning 18 hours postoperatively she experienced protracted vomiting which lasted twelve hours. The patient who had undergone debridement of humerus sat up to eat supper $2 \%$ hours after surgery.

\section{Discussion}

DFMTFCE appeared to have excellent possibilities as an anaesthetic agent when it was first administered to dogs. There was so little reaction to its use that we deliberately avoided removing food preanaesthetically from the cages of the dogs which received the drug seven times each. The rapid induction and recovery were encouraging. The lack of enzyme and BSP changes was also encouraging in the next series of measurements. When we had first been given the drug the accompanying oral information was that the drug does not sensitize the heart to epinephrine. Had this been true, it would have seemed that a distinct advantage over presently used agents had become available. Unfortunately and critically, this concept was not confirmed.

Tests of blood pressure when dogs were given DFMTFCE and later halothane indicated that the blood pressure was lower with halothane but that the difference was not statistically significant.

The latin square experiments indicated that anaesthesia was at least as smooth with DFMTFCE as with the other drugs and that no liver or kidney damage could be found with the tests utilized. Induction was least smooth with fluroxene, and the greatest variation in results occurred with the latter drug. SGOT and SGPT values were higher with fluroxene during anaesthesia, but were always back to control values within two days. This effect seems to be species-variable, for previous tests with dogs and man have differed using fluroxene. The concentrations required for DFMTFCE were just about double those required for halothane, so there is no question about the feasibility of administering high concentrations of oxygen ( $>95 \%$ ) when using DFMTFCE. The spontaneous muscle contractions about the eyes and limbs were never seen in light planes of anaesthesia. It should be considered that this phenomenon may be a warning sign of increasing depth of anaesthesia rather than an indication that anaesthesia 
is light and that depth should be increased further because of the movements. Muscle relaxation was good. Orotracheal intubation could be performed easily without the use of adjuvants.

Induction of volunteer subjects proceeded with ease. When this was done rapidly, however, it was necessary to use intermittent positive pressure breathing, for apnoea ensued easily. Endotracheal intubation was easily done, and bucking on the tube was almost entirely absent. As with halothane, the response to painful stimuli did not immediately disappear. Responses occurred even when the blood pressure had dropped as much as $30 \mathrm{~mm}$. Hg.

Variation in recovery sequences renders it difficult to generalize concerning residual effects of the drug. When similar measurements were made using halothan $e^{11}$ similarly variable results were encountered.

Relaxants for the surgical procedure were used only once in the eleven clinical cases, and this when the plane of anaesthesia was inadvertently permitted to become too light. The course of anaesthesia was quite similar to what we had experienced during the early use of halothane. The blood pressure dropped and analgesia was inadequate when unconsciousness was first attained. Induction and recovery were a little more rapid than with halothane. The vomiting mentioned occurred in a patient who was in deeper anaesthesia than necessary. There were no complaints about the agent on the part of the patients.

DFMTFCE appears to be similar to halothane, with the exception that, in the former, spontaneous movements are observed during the deeper planes. This may be a valuable feature.

\section{SUMMARY}

1. Difluoromethyl 1,1,2-trifluoro-2-chloro ethyl ether (DFMTFCE), a proposed new anaesthetic agent, was administered to dogs by open-drop and produced smooth anaesthesia without salivation, irritation, or nausea.

2. When epinephrine was given intravenously to 16 dogs asleep with DFMTFCE, three went into ventricular fibrillation.

3. The concentration of DFMTFCE required for surgical anaesthesia was roughly twice that with halothane for the same animals.

4. A latin square administration of DFMTFCE, halothane, methoxyflurane, and fluroxene demonstrated no significant effects on liver enzyme activity following the use of any of the drugs.

5. Blood glucose rose moderately with DFMTFCE; urea nitrogen was unchanged.

6. In eight volunteer subjects, DFMTFCE afforded a pleasant induction. Blood pressure dropped, as did cardiac output when anaesthesia deepened. The degree of analgesia was similar to that experienced with halothane. Spontaneous respiration ceased on attainment of surgical anaesthesia. Changing from oxygen to air produced mild hypoxaemia, at which time cardiac output increased. Waking was rapid. Three of the eight volunteers were nauseated for a short time during recovery.

7. Eleven surgical patients were given DFMTFCE for anaesthesia; the course was similar to that with halothane. 


\section{RÉSUMÉ}

L'administration, en goutte à goutte, de l'éther difluoro 1, 1, 2-trifluoro-2-chloro éthyle (DFMTFCE) à des chiens a produit une anesthésie douce et sans salivation. L'induction et le réveil ont été rapides et 'sans nausée ni vomissement.

Une heure d'anesthésie avec DFMTFCE chez des chiens a élevé légèrement le taux du glucose sanguin; l'azote uréique et les taux de plusieurs ensymes sont demeurés stables. L'administration d'épinéphrine, par voie endoveineuse, a entrainé une fibrillation ventriculaire chez trois chiens sur 16.

Une expérience (carré latin) où ont été employés, durant deux heures, le DFMTFCE, le méthoxyflurane, l'halothane et le fluroxène n'a montré aucun changement important des enzymes hépatiques ou de l'activité BSP d'aucun animal.

Une anesthésie profonde au DFMTFCE, chez huit volontaires, a diminué la respiration, la tension sanguine et le débit cardiaque. Le réveil a été rapide.

Le DFMTFCE a été donné comme agent anesthésique à onze opérés. L'allure de l'anesthésie a été comparable à celle que nous observons avec l'halothane.

\section{ACKNOWLEDGMENTS}

The authors would like to acknowledge the co-operation of C. K. Anderson, D.V.M., and A. F. Alexander, D.V.M., in reviewing the sections of tissues removed from the dogs. They are also grateful for the aid of Daniel Cooley in the determination of cardiac output.

\section{REFERENCES}

1. Meex, W. J.; Hathaway, H. R;; \& ORth, O. S. The Effects of Ether, Chloroform, and Cyclopropane on Cardiac Outomaticity. J. Pharmacol. \& Exper. Therap. 61: 240 (1937).

2. Netson, N. Photometric Adaption of Somogyi Method for Determination of Glucose. J. Biol. Chem. 153: 375 (1944).

3. KARR, W. G. Method for Determination of Blood Urea Nitrogen, J. Lab. \& Clin. Med. 9: 329 (1924).

4. Smbley, J. A. \& Lefhninger, A. H. Determination of Aldolase in Animal Tissues. J. Biol. Chem. 153: 375 (1944).

5. BELL, J. K. \& BARON, D. N. Colorimetric Estimation of Serum Isocitric Dehydrogenase. J. Clin. Path. 12: 582 (1959).

6. Reitman, S. \& Frankel, S. A Colorimetric Method for the Determination of Serum Glutamic Oxaloacetic and Glutamic Pyruvic Transaminases. Am. J. Clin. Path. 28: 56 (1957).

7. De Rrtis, F.; ColtontI, M.; \& Grustr, G. Attivita Transaminasica del Serio Umano Nell'spatite Virale. Minerva med. 46: 1207 (1955).

8. WROBLEWSKr, F. \& Grecony, K. Lactic Acid Dehydrogenase Isoenzymes and Their Distribution in Normal Tissues and Plasma in Disease States. Ann. New York Acad. Sc. 94: 912 (1961).

9. Green, M. N.; Tsou, K-C.; Bressler, R.; \& Seligman, A. M. The Colorimetric Determination of Leucine Amino Peptidase Activity with L-Leucyl- $\beta$-Nephthylamide Hydrochloride. Arch. Biochem. Biophys. $57: 458$ (1955).

10. Secoinger, S. I. Catheter Replacement of the Needle in Percutaneous Arteriography: A New Technique. Acta radiol. 39: 368 (1953).

11. Virtue, R. W.; VoGel, J. H. K.; Press, P.; \& Grover, R. F. Respiratory and Hemodynamic Measurements during Anesthesia: Use of Trifluoroethyl Vinyl Ether and Halothane. J.A.M.A. 179: 224 (1962). 